\title{
EFFECT OF WATER AND ALKALI CONTENT ON SETTING TIME OF CEMENT PASTES WITH ELECTRIC ARC FURNACE DUST (EAFD)
}

\author{
Margareth da Silva Magalhães ${ }^{1 *}$, Flora Faleschini ${ }^{2}$, Carlo Pellegrino ${ }^{2}$, Katya \\ Brunelli ${ }^{3}$
}

${ }^{1}$ Dept. of Civil Construction and Transport, State University of Rio de Janeiro, Rua São Francisco Xavier, 524, 5005-A, CEP 20550-900, Rio de Janeiro-RJ, Brazil.

${ }^{2}$ Dept. of Civil, Environmental and Architectural Engineering, University of Padua, Via Marzolo 9, 35131 Padua, Italy.

${ }^{3}$ Dept. of Industrial Engineering, University of Padua, Via Marzolo 9, 35131 Padua, Italy.

*corresponding author: margareth.magalhaes@uerj.br

\begin{abstract}
This study was undertaken to provide additional information about the effects of varying water-binder ratio (0.30-0.55) and electric arc furnace dust (EAFD) content (up to 20\%) on setting times of blended cements. A study about the influence of total alkali content on setting time of blended cement was also conducted as an attempt to identify an efficient pre-treatment system to solve the retardation influence of such dust on setting time. Results indicate that the use of low w/b ratio is effective in shortening the setting time of blended cements, limiting the setting time below $24 \mathrm{~h}$ in most of the analysed mixtures. Increasing the alkali content was also effective on shortening the setting time of blended pastes. Final setting time of pastes with $10 \%$ and $20 \%$ EAFD was less than 6 hours, and when the EAFD content was 5\%, setting times was almost the same of the cement paste.
\end{abstract}

Keywords: Setting time; electric arc furnace dust; mineral addition; blended cement; alkali

\section{INTRODUCTION}

The electric arc furnace dust (EAFD) is a solid wastes formed in the steelmaking process. It is a fine-grained material, containing significant amounts of zinc and iron together with variable amounts of calcium, manganese, magnesium, silicon and chromium (Magalhães et al 2017a), however, the composition of EAFD is variable and depends on scrap used, and the ratio of galvanized scrap utilized during steelmaking process (Orhan 2005, Salihoglu and Pinarli 2008).

In the literature, some works attempted to explore the suitability of its application both in ceramics [Stathopoulos et al, 2013] and cement-based materials (Magalhães et al 
2017a, Al-Zaid et al 1997, Vargas et al 2006, Maslehuddin et al 2011, Al-Mutlaq and Page 2013, Fares et al 2016). In these research works, it was observed that the cementmixtures containing up to 5\% EAFD exhibited superior mechanical behaviour when compared to reference samples. However, blended cement with EAFD react more slowly than Portland cement due to the presence of zinc oxide in the dust that acts as a retardant in the setting times (Magalhães et al 2017a, Vargas et al 2006, Maslehuddin et al 2011, Al-Mutlaq and Page 2013, Fares et al 2016, Arliguie and Grandet 1990, Balderas et al 2001, Hamilton and Sammes 1999).

According to Al-Zaid et al. (1997) and Fares et al. (2016), the extension of setting time may exceed $33 \mathrm{~h}$ with just an addition of $3 \%$ of dust. Hamilton and Sammes (1999) verified that specimens with $10 \%$ of EAFD had the same 28 -days compressive strength to that of the reference specimens after 56 days of ageing, displaying a significant delayed strength evolution. This behaviour was related to the delayed hydration process often observed in blended cements with EAFD.

Although a significant literature already exists about this material, too little effort was paid to minimize or solve the main criticism of EAFD addition, i.e. its retarding effect on setting time, particularly at high dosages. The retarding effect due to zinc oxide presence in EAFD has hindered, until now, its application in blended mixtures at elevated dosage (more than 3\%) and little literature exists about using EAFD addition on cement-based-mixtures, particularly at high dosages.

Balderas et al. (2001) demonstrated that the addition of 8 and $10 \%$ of treated EAFD with a $\mathrm{H} 2 \mathrm{SO} 4$ solution produced retardation of the setting process and decreases earlyage compressive strength, but increased it significantly after seven days. Al-Mutlaq and Page (2013) found that the use of 3.5\% non-chloride accelerators was ineffective in reducing setting time of concretes with $8 \%$ of EAFD.

The principal factors that control setting time of cement based materials are: cement composition, water-cement ratio, temperature, mineral and chemical admixtures presences, etc (Metha and Monteiro 2006). Hence, a suitable way to limit setting time of pastes is to reduce the effective water content inside the mixtures, by changing the mixture composition or EAFD treatment.

In literature, it is generally considered that, for conventional cement-based-materials potassium and sodium ions (present along with either sulfates or hydroxides) accelerate the early hydration of cement, while resulting in reduced hydration and strength at later ages (Jawed and Skalny 1978, Maycock and Skalny 1974, Stein 1961, Odler and Wonnemann 1983). The early set acceleration by alkalis has been attributed to an enhancement of the solubility of aluminate (Mota et al 2015), of the rate of dissolution of the calcium silicate phases and precipitation of the hydrated phases (Mori et al 1969, Mori et al 1971, Garci and Jennings 2002, Bentz 2006).

Differently from previous studies, the purpose of this work is to provide additional information about the effects of water-binder $(\mathrm{w} / \mathrm{b})$ ratio and EAFD content on setting times of blended cements. Additionally, a study about the influence of total alkali content on setting time of blended cement was also conducted as an attempt to identify an efficient pre-treatment system to solve the retardation influence of such dust on setting time. Shorter setting times allow to reduce the time for formwork removal from in-situ cast concrete or mold stripping in the manufacture of precast concrete products, as well as concreting in cold climates. Hence, here a simple set test based on Vicat 
apparatus was used to analyze the changes in set of blended cements with varying EAFD, w/b ratio and alkali content.

\section{EXPERIMENTAL PROGRAM}

\subsection{Materials}

Portland cement, electric arc furnace dust (EAFD), tap water and reagent-grade sodium hydroxide $(\mathrm{NaOH})$ in pellet were the materials used to prepare the mixes. The cement used is a rapid setting ordinary Portland cement type I 52.5R, as defined in the BS-EN 197-1 (2011), with a density of $3.08 \mathrm{~g} / \mathrm{cm}^{3}$. EAFD is used in as-received condition from the dust collection system of a carbon steelmaking factory in Italy, and has a density of $3.49 \mathrm{~g} / \mathrm{cm}^{3}$.

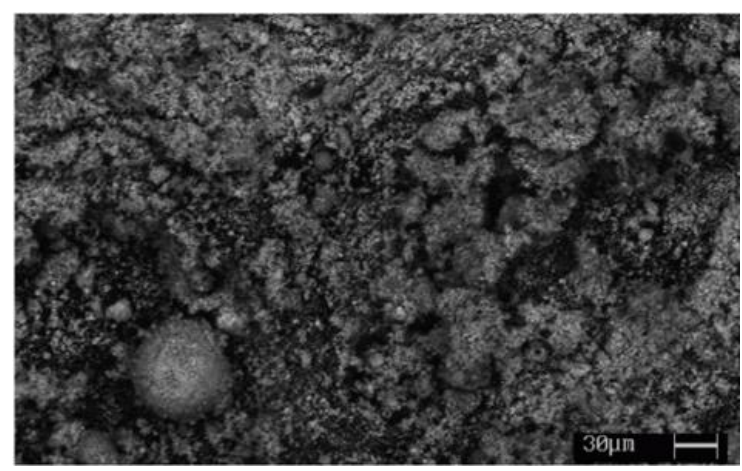

Figure 1. Scanning electron microscope image of EAFD sample.

The EAFD used in this study is a dust composed of ultrafine and spherically shaped particles (Figre 1) rich in $\mathrm{Zn}(31.34 \%), \mathrm{Fe}(35.92 \%)$ and $\mathrm{Ca}(13.32 \%)$ oxides, with few quantity (<4\%) of $\mathrm{Si}, \mathrm{Mg}$, Mn and $\mathrm{Pb}$ oxides (Magalhães et al 2017a). Figure 2 shows articles size distribution of cement and EAFD, as they are obtained using laser diffraction technique. EAFD has a wide range of particle sizes, with coarser particles having a diameter up to $478 \mu \mathrm{m}$. The characteristics of the distribution are: $\mathrm{d}_{10}$ equal to $2.57 \mu \mathrm{m}$; median particle size $\mathrm{d}_{50}$ of $10 \mu \mathrm{m}$ and $\mathrm{d}_{90}$ is $67.58 \mu \mathrm{m}$. Cement is characterized instead by $\mathrm{d}_{10}=1.35 \mu \mathrm{m}, \mathrm{d}_{50}=10.68 \mu \mathrm{m}$ and $\mathrm{d}_{90}=32.75 \mu \mathrm{m}$, being finer than the EAFD used in this work.

\subsection{Mixture Details}

The experimental program aims to study blended cement pastes with varying EAFD, water and alkali content. Six reference pastes (with no EAFD) and six paste mixtures with $5 \%$ EAFD and $w / b$ ratio between 0.30 and 0.55 were prepared to study the effect of water content. Other eight pastes mixtures with six alkali $\left(0.59-4.31 \% \mathrm{Na}_{2} \mathrm{O}_{\mathrm{e}}\right.$ by mass of overall binder) content and three EAFD (5\% - 20\%) amounts were also prepared, maintaining a fixed water/overall binder $(\mathrm{w} / \mathrm{b})$ ratio of 0.35 . Cement and EAFD were considered as binder (b) to calculate the water content without considering dust efficiency (Magalhães et al 2017b). 


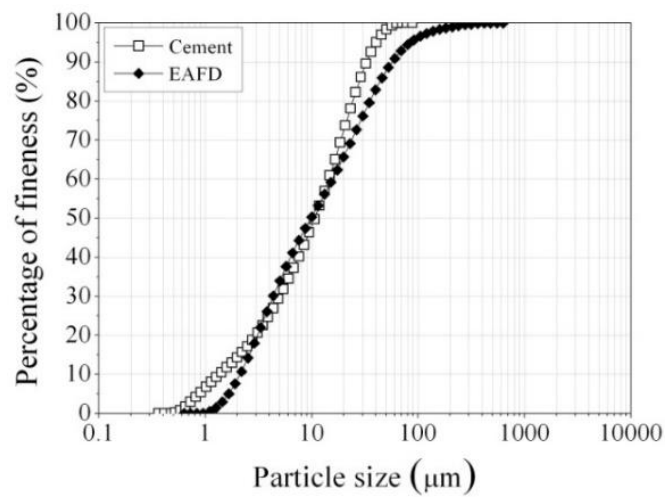

Figure 2. Particle size distribution of cement and EAFD.

The paste mixture with the lowest alkali content $\left(0.59 \% \mathrm{Na}_{2} \mathrm{O}_{\mathrm{e}}\right.$ by mass of overall binder) was prepared using the original cement. Higher alkali contents were achieved by adding reagent-grade sodium hydroxide $(\mathrm{NaOH})$ in pellet form to the mixing water and stirring until the $\mathrm{NaOH}$ had totally dissolved. The $\mathrm{NaOH}$ solution was then added to the mixer. The $\mathrm{NaOH}$ additions were $0.12 \%, 1.2 \%, 2.4 \%, 3.6 \%$ and $4.8 \%$ (by mass of binder), which correspond to total alkali contents of $0.69 \%, 1.52 \%, 2.45 \%, 3.38 \%$ and $4.31 \% \mathrm{Na}_{2} \mathrm{O}_{\mathrm{e}}$, respectively (by mass of binder).

\subsection{Experimental Methods}

Initial and final setting times were determined using an automatic setting time machine based in the Vicat apparatus (EN 196-3 2016). This equipment measures paste resistance to the penetration of a needle under a load of $300 \mathrm{~g}$. The time elapsed between zero and the instant at which the distance between the needle and the baseplate is $6 \pm 3 \mathrm{~mm}$ is taken as the initial set time. In this test, final setting time was considerate as the time elapsed between zero and the instant at which the needle penetrates the paste to a maximum depth of $3 \mathrm{~mm}$. Instant zero is considered from the moment when mixing water is added to the mixture. Set tests were carried out in a room with relative humidity and temperature of $54-75 \%$ and $19 \pm 1.0^{\circ} \mathrm{C}$, respectively.

\section{EXPERIMENTAL RESULTS}

\subsection{Setting Time Dependency on W/B Content}

The dependence of setting time on the variation of w/b is shown in Figure 3, both for the ordinary cement and blended cement with 5\% EAFD content. Set tests were carried out in a room with relative humidity and temperature of $54 \pm 2.0 \%$ and $19 \pm 1.0{ }^{\circ} \mathrm{C}$, respectively. Particularly, it is possible to observe the influence of varying w/b ratio on setting time. As expected, both initial and final setting time display a strong dependency on water content and dust addition. 


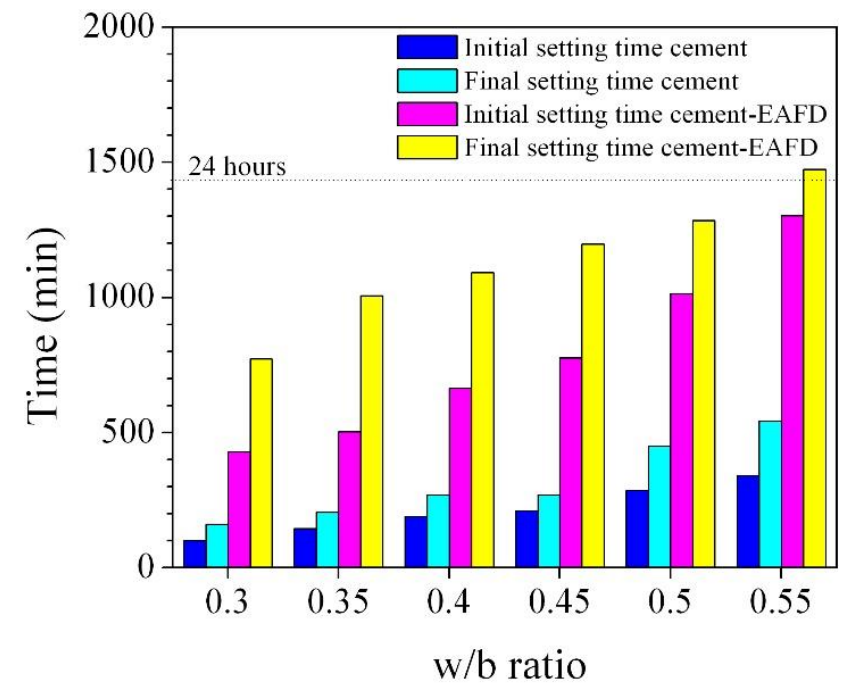

Figure 3. Relationship between $\mathrm{w} / \mathrm{b}$ ratio and initial and final setting time of cement and mixtures with 5\% EAFD.

Values in the Figure 3 indicate that the reduction of $w / b$ ratio is very significant to reduce setting time, in a similar extent as in the blended paste, as in ordinary cement. Indeed, initial setting time decreases from $1303 \mathrm{~min}(21.72 \mathrm{~h})$ to $428 \mathrm{~min}(7.13 \mathrm{~h})$, when w/b ratio changes from 0.55 to 0.30 in $5 \%$ EAFD paste, whereas it varies between $342 \mathrm{~min}(5.70 \mathrm{~h})$ to $101 \mathrm{~min}(1.68 \mathrm{~h})$ within the same range for cement pastes. This result can be easily explained because setting and hardening phenomena are influenced by the filling of void space with the products of hydration (Metha and Monteiro, 2006), and hence the water-binder ratio obviously affects the initial and the final set times.

Additionally, it was possible to achieve, for the majority of the cases, the target objective of limiting both initial and setting time below $24 \mathrm{~h}$, when 5\% of EAFD was used. Only the mixture with the highest $w / b$ ratio, i.e. $w / b=0.55$, displayed a final setting time slightly longer than $24 \mathrm{~h}$ (approximately $24.6 \mathrm{~h}$ ).

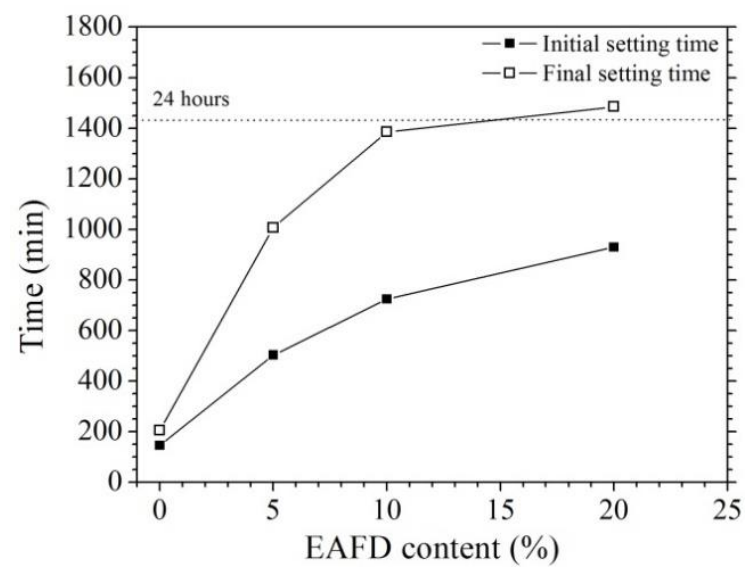

Figure 4. Setting times of cement (reference) and pastes with 5\%-20\% EAFD. 
Setting time of blended cement with up to $20 \%$ EAFD and w/b ratio (0.35) is shown in the Figure 4. As expected, both initial and final setting time displays a strong dependency on dust addition, which is directly dependent on the amount of the dust addition.

Initial setting time increased from $146 \mathrm{~min}$ in the reference paste to $503 \mathrm{~min}, 725 \mathrm{~min}$ and 930 min for the mixtures containing 5\%,10\% and 20\% of EAFD, respectively. The same occurred for the final setting time, which increased from $206 \mathrm{~min}$ in the reference paste to $1007 \mathrm{~min}, 1385 \mathrm{~min}$ and $1485 \mathrm{~min}$ for the mixtures containing 5\%, $10 \%$ and $20 \%$ of EAFD, respectively. The relative increase in initial setting time was of $340 \%$ (5\% EAFD), 500\% (10\% EAFD) and 640\% (20\% EAFD); in the final setting time it was of $490 \%$ (5\% EAFD), 670\% (10\% EAFD) and $720 \%$ (20\% EAFD), if compared to the ordinary cement paste.

This typical set retardation observed in the cement blended with EAFD is directly assigned to the effect of $\mathrm{Zn}^{2+}$ introduction into the paste, which is considered an inhibitor of $\mathrm{C}_{3} \mathrm{~S}$ or cement hydration (Taylor 1997, Chen et al 2009). Indeed, $\mathrm{Zn}^{2+}$ delays the early hydration of $\mathrm{C}_{3} \mathrm{~S}$, which could arise from the precipitation of calcium zincate $\left(\mathrm{CaZn}_{2}(\mathrm{OH})_{6} \cdot 2 \mathrm{H}_{2} \mathrm{O}\right)$ (Chen et al 2009). Calcium zincate coats $\mathrm{C}_{3} \mathrm{~S}$ grains, thus reducing material transport necessary for $\mathrm{C}_{3} \mathrm{~S}$ hydration (Chen et al 2009), causing the delayed set observed in this work. According to Vargas et al. (2006), the "dormant period", during which the hydration rate is very low and the paste is workable, is longer in EAFD-cement paste than in cement paste and depends on EAFD content.

Although data in the literature show a negative influence of EAFD addition on setting time, it is significant to note that the combined effect of using high EAFD content and reduced w/b ratio was effective to shorten the setting time of blended pastes, when compared with results commonly presented by other authors (Al-Zaid et al. 1997, Fares et al. 2016) who used higher w/b ratio and lower EAFD content than here. Final setting times of 5 and 10\% EAFD mixtures were less than $24 \mathrm{~h}$, and setting time of $20 \%$ EAFD was only slightly higher than $24 \mathrm{~h}(24.75 \mathrm{~h})$.

\subsection{Setting Time Dependency on Alkali Content}

The addition of 5\% EAFD (replacing cement) severely lengthens the times of set compared to ordinary cement, as previously reported in the section 3.1. However, the addition of $\mathrm{NaOH}$ between $0.12 \%-4.8 \%$ of the overall binder decreases the length of the setting times, as seen in the Figure 5. These effects are accentuated with the augment of $\mathrm{NaOH}$ content and at $3.6 \% \mathrm{NaOH} / \mathrm{b}$, the difference between cement blended with 5\% EAFD and cement paste is almost non-existent. In this study, the tests were carried out in a room with relative humidity and temperature of $75 \pm 4.0 \%$ and $19 \pm 1.0^{\circ} \mathrm{C}$, respectively.

Comparing the values in the Figure 5, it is visible that the addition of $\mathrm{NaOH}$ was effective to reduce the set time, even in the lowest levels of addition. Indeed, initial setting time decreased from $806 \mathrm{~min}(13.43 \mathrm{~h})$ to $487 \mathrm{~min}(8.12 \mathrm{~h})$ and final setting time decreased from $1086 \mathrm{~min}(18.09 \mathrm{~h})$ to $697 \mathrm{~min}(11.62 \mathrm{~h})$, with $0.12 \% \mathrm{NaOH}$ (by mass of binder). The time of both initial and final setting decreased continuously as the alkali content increased, and the typical delay in setting times of cement blended with 5\% EAFD was not observed. When a $\mathrm{NaOH} / \mathrm{b}$ content of $3.6 \%$ and $4.8 \%$ was added to mixture, setting time was similar or even lower than in the cement paste. This 
outcome displays the same tendency evidenced in past studies conducted on ordinary cement pastes, where the increasing alkali content enhanced the rate of cement hydration and promoted setting (Jawed and Skalny 1978, Maycock and Skalny 1974, Stein 1961, Odler and Wonnemann 1983).

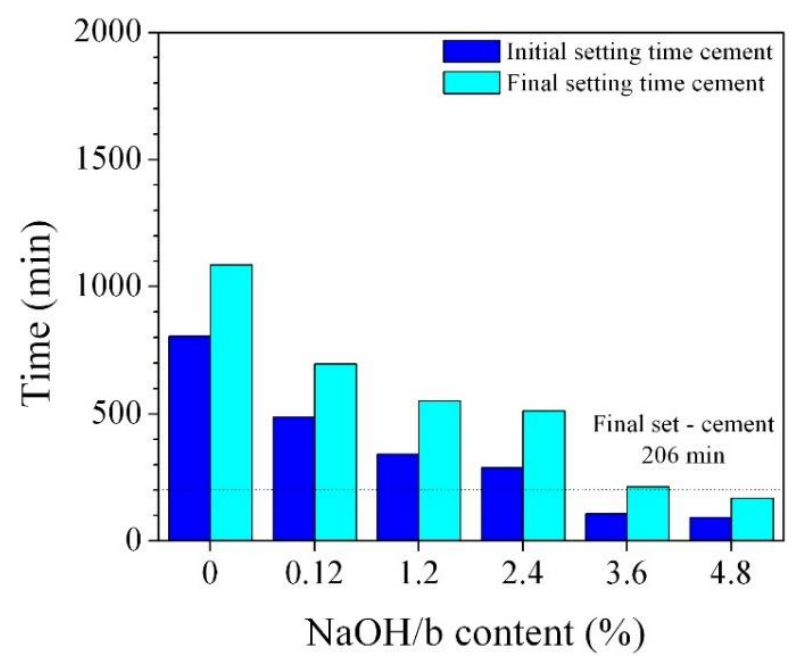

Figure 5. Relationship between $\mathrm{NaOH} / \mathrm{b}$ content and setting times.

The early set acceleration displayed by alkalis addition has been attributed to some concurrent causes, including an enhancement of the solubility of aluminate (Mota et al 2015 ), of the rate of dissolution of calcium silicate phases and to the precipitation of hydrated phases ((Mori et al 1969, Mori et al 1971, Garci and Jennings 2002, Bentz 2006). A study carried out by Kumar et al. (2012) about alite $\left(C_{3} S\right)$ hydration reported that sodium hydroxide increases the $\mathrm{pH}$ when added to mixing water, and thereafter it accelerates the rate of hydration and reduces the duration of the induction, acceleration and deceleration regimes.

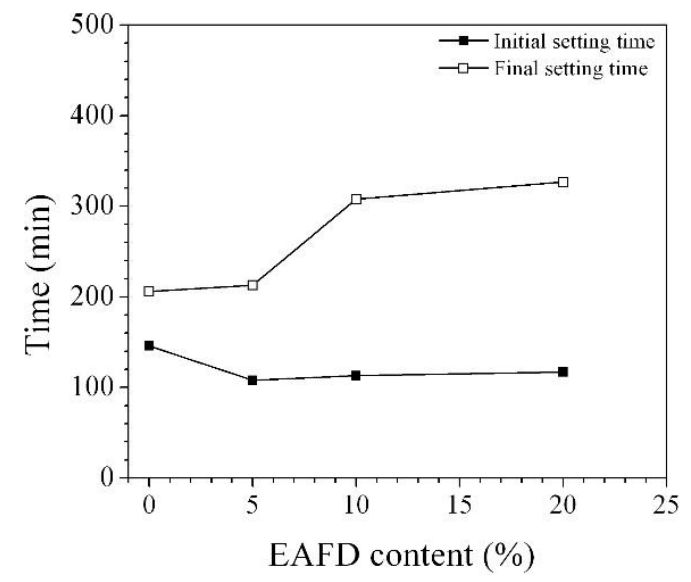

Figure 6. Setting times of cement and pastes with 5\%-20\% EAFD and $\mathrm{NaOH}$ content of $3.6 \%$ (expressed as a concentration of the overall binder). 
Once verified the dependency of setting time evolution on $\mathrm{NaOH}$ content, the initial and final setting times were experimentally measured for mixtures containing up to $20 \%$ of EAFD and fixed $\mathrm{NaOH} / \mathrm{b}$ content to $3.6 \%$ and $\mathrm{w} / \mathrm{b}$ ratio to 0.35 (Figure 6). The severe retardant effect in cement setting often observed when this dust is used, as seen in the section 3.1, was minimized with the addition of $\mathrm{NaOH} / \mathrm{b}$ equal to $3.6 \%$. With such alkali content, cement pastes blended with 5\%,10\% and 20\% EAFD presented initial setting time (between $1.80-1.95 \mathrm{~h})$ lower than cement paste $(2.43 \mathrm{~h})$. However, the final setting times of cement pastes systems blended with $10 \%(5.13 \mathrm{~h})$ and $20 \%$ $(5.45 \mathrm{~h})$ EAFD were higher than that of the reference paste $(3.43 \mathrm{~h})$ and cement blended with $5 \%(3.55 \mathrm{~h})$. The relative increase in final setting time was $49.5 \%(10 \%$ EAFD) and $58.8 \%$ (20\% EAFD) if compared to the reference mixture.

\section{CONCLUSIONS}

In this study, the influence of water, EAFD and total alkali content of EAFD-cement mixture on setting time of blended cement pastes was analyzed. This research work aims to represent a first attempt to identify an efficient pre-treatment to solve the late setting typically experienced by mixtures with high EAFD content (more than 3\% on cement weight). Based on the experiment results derived in this research, the following conclusions are drawn:

- A high dependency on water-to-binder ratio has been displayed by the analysed blended pastes. Hence, it was possible to assess relationships able to predict both initial and final setting times, knowing the w/b content in ordinary and blended cements. In the analyzed w/b (0.30-0.55), most of the pastes exhibited setting before $24 \mathrm{~h}$;

- Setting time is highly EAFD content-dependent. Even though this result is not a novelty, it is worth to note that the combined effect of high EAFD dosage and reduced $\mathrm{w} / \mathrm{b}$ ratio allows to achieve set before the target of $24 \mathrm{~h}$ in most of the cases. Indeed, final setting time of mixtures with 5 and $10 \%$ EAFD were less than $24 \mathrm{~h}$; only in the case of an addition of $20 \%$, setting time was slightly higher than $24 \mathrm{~h}(24.75 \mathrm{~h})$;

- The addition of $\mathrm{NaOH}$ was effective on shortening both initial and final setting time, and this effect is proportional to the $\mathrm{NaOH}$ concentration. With $\mathrm{NaOH} / \mathrm{b}$ content of $3.6 \%$ and $4.8 \%$, cement paste with 5\% EAFD displays initial and final setting time similar to that of the ordinary cement and the final setting times of $10 \%$ and $20 \%$ EAFD mixtures were less than 6 hours.

\section{ACKNOWLEDGMENTS}

The authors acknowledge the Quality Improvement Program for Universities of the Ministry of Education and Culture (CAPES) for the financial support and Acciaierie Venete SpA for supplying the EAFD. 


\section{REFERENCES}

Al Mutlaq F.M., Page C.L. (2013). Effect of electric arc furnace dust on susceptibility of steel to corrosion in chloride-contaminated concrete. Constr Build Mater 39: 60-64. https://doi.org/10.1016/j.conbuildmat.2012.05.008

Al-Zaid R.Z., Al-Sugair F.H., Al-Negheimish A.I. (1997). Investigation of potential uses of electric-arc furnace dust (EAFD) in concrete. Cem Concr Res 27(2): 267-278. https://doi.org/10.1016/S0008-8846(96)00204-9

Arliguie G., Grandet J. (1990). Influence de la composition d'un ciment Portland sur son hydratation em presence de zinc. Cem Concr Res 20(3): 517-524. https://doi.org/10.1016/0008-8846(90)90096-G

Balderas A., Navarro H., Flores-Velez L.M., Dominuez O. (2001). Properties of Portland cement pastes incorporating nanometer-sized franklinite particles obtained from electric arc furnace dust. J Am Ceram Soc 84(12): 2909-2913.

Bentz D.P. (2006). Influence of alkalis on porosity percolation in hydrating cement pastes. Cem. Concr. Compos. 28: 427-431. https://doi.org/10.1016/j.cemconcomp.2006.01.003.

Chen, Q.Y., Tyrer, M., Hills, C.D., Yang, X.M., Carey, P. (2009). Immobilisation of heavy metal in cement-based solidification/stabilisation: A review. Waste Manage 29(1): 390-403.

EN 196-3 (2016). Methods of testing cement. Determination of setting times and soundness. Comité Européen de Normalisation, Brussels, Belgium.

EN 197-1 (2011). Cement. Composition, specifications and conformity criteria for common cements, Brussels, Belgium.

Fares G., Al-Zaid R.Z., Fauzi A., Alhozaimy A.M., Al-Negheimish A.I., Khan M.I. (2016). Performance of optimized electric arc furnace dust-based cementitious matrix compared to conventional supplementary cementitious materials. Const Build Mater 112(1): 210-221. https://doi.org/10.1016/j.conbuildmat.2016.02.068.

Garci Juenger M.C., Jennings H.M. (2002). Examining the relationship between the microstructure of calcium silicate hydrate and drying shrinkage of cement pastes. Cem. Concr. Res. 32: 289-296. https://doi.org/10.1016/S00088846(01)00673-1.

Hamilton I.W., Sammes N.M. (1999). Encapsulation of steel foundry bag house dusts in cement mortar. Cem Concr Res 29(1): 55 - 61. https://doi.org/10.1016/S0008-8846(98)00169-0.

Jawed I., Skalny J.P. (1978). Alkalies in cement: A review II. Effects of alkalies on hydration and performance of Portland cement. Cem Concr Res 8:37-52. https://doi.org/10.1016/0008-8846(78)90056-X.

Kumar A., Sant G., Patapy C., Gianocca C., Scrivener K.L. (2012). The influence of sodium and potassium hydroxide on alite hydration: experiments and 
simulations. Cem. Concr. Res. 42: 1513-1523. https://doi.org/10.1016/j.cemconres.2012.07.003.

Magalhães M.S., Faleschini F., Pellegrino C., Brunelli K. (2017a). Effects of Electric Arc Furnace dust (EAFD) addition on setting and strength evolutions of cement pastes and mortars. Eur $J$ Civ Environ Eng: 1-13. https://doi.org/10.1080/19648189.2017.1357776.

Magalhães MS, Faleschini F, Pellegrino C, Brunelli K. (2017b). Cementing efficiency of electric arc furnace dust in mortars. Constr Build Mater, 157: 141-150. https://doi.org/10.1016/j.conbuildmat.2017.09.074.

Maslehuddin M., Awan F.R., Shameem M., Ibrahim M., Ali M.R. (2011). Effect of arc furnace dust on the properties of OPC and blended cement concretes. Constr Build Mater 25: 308-312. https://doi.org/10.1016/j.conbuildmat.2010.06.024.

Maycock J.N., Skalny J. (1974). Hydration of Ca3SiO5.K2C03 system. Thermochim. Acta 8: 167-176. https://doi.org/10.1016/0040-6031(74)85083-5.

Mori H., Minegishi K., Ohta T. (1969). Early hydration of 3CaO $\mathrm{SiO} 2$ in the presence of alkali. In: Proc. 23rd Gen. Meet. Cem. Assoc. Japan, 1969. 58-60.

Mori H., Minegishi K., Ohta T., Akiba T. (1971). The effect of alkali on the microstructure of hardened $3 \mathrm{CaO} \cdot \mathrm{SiO} 2$ paste. In: Proc. 25 th Gen. Meet. Cem. Assoc. Japan1971. 33-37.

Mota B., Matschei T., Scrivener K. (2015).The influence of sodium salts and gypsum on alite hydration. Cem and Concr Res. 75: 53-65, https://doi.org/10.1016/j.cemconres.2015.04.015.

Odler I., Wonnemann R. (1983). Effect of alkalies on portland cement hydration II. Alkalies present in form of sulphates, Cem. Concr. Res. 13: 771-777. https://doi.org/10.1016/0008-8846(83)90078-9

Orhan, G. (2005). Leaching and cementation of heavy metals from electric arc furnace dust in alkaline medium. Hydrometallurgy 78: 236-245. https://doi.org/10.1016/j.hydromet.2005.03.002.

Salihoglu G., Pinarli V. (2008). Steel foundry electric arc furnace dust management: stabilization by using lime and Portland cement. J Hazard Mater 153: 11101116. https://doi.org/10.1016/j.jhazmat.2007.09.066.

Stathopoulos V.N., Papandreou A., Kanellopoulou D., Stournaras C.J. (2013). Structural ceramics containing electric arc furnace dust. J Hazard Mater 262: 91-99. https://doi.org/10.1016/j.jhazmat.2013.08.028.

Stein H. (1961). Influence of some additives on the hydration reactions of Portland cement I. Non-ionic organic additives. J. Appl. Chem. 11: 474-482.

Taylor, H.F.W. (1997). Cement Chemistry, second ed. Thomas Telford Press, London.

Vargas A., Masuero A.B., Vilela A.C.F. (2006). Investigations on the use of electric arc furnace dust (EAFD) in pozzolan-modified Portland cement I (MP) pastes. 
